\title{
É A DIALÉTICA, NO SENTIDO DA TRADIÇÃO, UMA DOGMÁTICA OBJETIVO-METAFÍSICA?
}

Manfredo Araujo de Oliveira*

SINTESE - K. O. Apel vê na Dialética uma dupla tarefa. Ela, por um lado, tem que ser um método de estruturar o discurso filosófico; por outro lado, ela tem que dar conta da historicidade com seus fatos contingentes. Se o primeiro aspecto predomina $e$ é levado às últimas conseqüências, a historicidade desaparece $e$ os fatos perdem sua contingência, como em Hegel e Marx. Se o segundo aspecto predomina e é levado a sério, o método deixa de ser método. A Hermenêutica de Gadamer quer, por isso, substituir o primeiro aspecto, eliminando a Dialética como método. Apel tenta superar esses impasses, introduzindo uma conciliação do Apriori-Corpo com o Apriori-Consciência. $\mathrm{O}$ primeiro corresponde à historicidade, o segundo, à necessidade característica do método. Mas Apel pára aqui e não faz disso uma Ontologia; o que V. Hoesle e Cirne-Lima, continuando na montagem do mesmo raciocinio, tentam fazer.
ABSTRACT - K. O. Apel sees in Dialectics a twofold task: on the one hand, it must be a method able to structure the philosophical discourse; on the other hand, it must bear in mind the historicity with its contingent facts. If the first aspect prevails and is led to the last consequences, then historicity disappears and the facts loose their contingency, as it occurs in Marx and Hegel. If the second aspect is prevailing and seriusly assumed, then the method ceases to be method. Gadamer's hermeneutics therefore wants to substitute the first aspect, by elimination of Dialectics as a method. Apel, on the contrary, tries to surpass the impasse, introducing a conciliation of the body-a priori with the conscience-a priori. The former corresponds to the historicity, the latter to necessity characteristic of the method. But Apel stops here and leaves aside ontology. Going further on in the same reasoning, V. Hoesle and Cirne-Lima aim to construct an ontology.

\section{I - A concepção apeliana de dialética enquanto Lógica Filosófica da Situação}

\section{A - O dilema da dialética contemporânea}

O grande mérito da pragmática transcendental foi, a partir da reviravolta lingüístico-hermenêutica do pensamento, ter retomado a concepção tradicional de filosofia como teoria dos princípios, um saber, essencialmente, diferente do saber

Universidade Federal do Ceará, UFC.

\begin{tabular}{|l|l|l|l|l|l|}
\hline VERITAS & Porto Alegre & v. 41 & $\mathrm{n}^{2} 164$ & Dezembro 1996 & p. 637-656 \\
\hline
\end{tabular}


empírico das ciências por trabalhar reflexivamente, ${ }^{1}$ tendo, portanto, como tarefa específica, a explicitação dos pressupostos intranscendíveis enquanto condições de possibilidade e validade do próprio saber científico e, em última instância, as condições necessárias de todo discurso humano. Portanto, seu cerne está na articulação do "jogo de linguagem" próprio à filosofia, ${ }^{2}$ o que significa mostrar que filosofia é, em princípio, um saber transcendental $l^{3}$ enquanto tematização das pressuposições inelimináveis, não contingentes, do discurso válido do contingente. É neste esforço de articulação do específico da reflexão filosófica que podemos perguntar pela significação da Dialética, no pensamento de Apel.

A posição de Apel em relação à Dialética não é só uma posição negativa: ${ }^{4}$ ao contrário, ele tentou dar sua contribuição à resposta à questão que, hoje, está no centro da discussão filosófica, ${ }^{5}$ que é Dialética e o fez procurando pensar uma síntese entre duas posições extremas ${ }^{6}$ da história de influência do pensamento hegeliano. ${ }^{7}$ Para Apel, cada uma destas posições acentua uma das dimensões fundamentais da Dialética, ou seja, reflexão e práxis material, cuja mediação ${ }^{8}$ constitui propriamente a tarefa da Dialética enquanto articulação do sentido da situação histórica.

1 Para Apel, a filosofia não trabalha com o conhecimento enquanto derivação de algo a partir de algo, como faz, por exemplo, a ciência, mas é retomo reflexivo às condiçōes de validade da argumentação. Cf. K. O. Apel, Von Kant zu Peirce: Die semiotische Transformation der Transzendentalen Logik. In: Transformation der Philosophie. v. 2, Das Apriori der Kommunikationsgemeinschaft, Frankfurt am Main, 1976, p. 157-177. Em sua diferença com o discurso da lógica formal e com o discurso das ciências empíricas.

3 Não um saber direto de objetos, que é a especificidade das ciências, mas dos pressupostos de nossa compreensão dos objetos do mundo

4 Não só ao caráter metafísico-objetivo do materialismo dialético, mas à "pretensão ontológica" enquanto tal do pensamento dialético, pois, para Apel, a filosofia, enquanto reflexăo sobre as condiçōes de validade da argumentação, não pode fornecer uma explicaçăo ontológico-cosmológica do mundo. Cf. K. O. Apel, Fundamentação última não-metafísica. In: STEIN, E., DE BONI, L. (org.). Dialética e Liberdade. Festschrift em homenagem a Carlos Roberto Cime-Lima, Porto Alegre-Petropolis, 1993 , p. 317.

5 Cf. a respeito desta discussão: D. Wandschneider, Grundzüge einer Theorie der Dialektik. Rekonstruktion und Revision dialektischer Kategorienentwicklung in Hegels "Wissenschaft der Logik". Stuttgart, 1995.

6 Trata-se do "Criticismo dialético" de R. Hönigswald e Th. Litt e do "Materialismo dialético" da tradição marxista de pensamento.

7 Nos escritos de Apel, sobretudo em Diskurs und Verantwortung. Das Problem des Übergangs zur postkonventionellen Moral, Frankfurt am Main, 1988, há muitas referências ao "apriori dialético" enquanto diferença no apriori de uma dimensăo ideal (Um princípio-fundamento ideal) e de uma dimensão fática (O apriori da facticidade), o que Apel já havia trabalhado em: Das Apriori der Kommunikationsgemeinschaft und die Grundlagen der Ethik. Zum Problem einer rationalen Begründung der Ethik. In: Transformation der Philosophie, op. cit., p. 358-436. No entanto, Apel tenta, expressamente, explicitar sua contribuição à compreensão específica do que ele mesmo chama a essência da dialética no artigo: Reflexion und materielle Praxis: zur erkenntnisanthroplogischen Begründung der Dialektik zwischen Hegel und Marx. In: Transformation der Philosophie, op. cit., p. 9-27.

8 Em nenhum momento de sua consideração explícita sobre a dialética, Apel se refere ao jogo de opostos enquanto busca da síntese de contrários, numa categoria sintética, enquanto unidade de contrapostos. Por esta razão; para ele, a dialética não constitui propriamente o jogo de linguagem da filosofia, mas efetiva, enquanto pretende interpretar uma situação histórica, a combinação entre duas instâncias distintas da vida humana: a consciência e o engajamento corporal no mundo. 
O "criticismo dialético" ${ }^{9}$ trabalhou a problemática da teoria do conhecimento tematizando as pressuposições transcendentais da consciência, ou seja, as condições reflexivas da Dialética enquanto saber das condições universais de validade de nossos conhecimentos. Neste sentido, esta postura se situa na tradição crítica do idealismo moderno e atingiu, segundo Apel, o nível mais alto de reflexão crítica na filosofia mais recente, embora sua influência no pensamento contemporâneo tenha sido insignificante. $O$ que caracteriza esta postura é a consciência clara de que a tarefa própria da Filosofia se situa numa "reflexão formal" última sobre as condições de validade e de constituição das ciências particulares,${ }^{10}$ recusando-se a oferecer uma interpretação filosófica do conteúdo empírico do mundo fornecido pelas ciências. ${ }^{11}$

Por outro lado, o marxismo explica seu sucesso, além de outros motivos, por ter conservado o lado substancial da dialética hegeliana: ele se concentra na tematização do outro elemento constitutivo da Dialética, ou seja, o momento material da práxis humana, portanto, o momento da mediação prático-material de todo conhecimento humano. O grande mérito do marxismo, para Apel, consistiu, precisamente, em ter sido capaz de elaborar uma visão de mundo que, sendo mediada pelas ciências, possui conteúdo, o que a Filosofia sozinha, enquanto reflexão formal, não pode dar. Além disto o marxismo é, ao mesmo tempo, capaz de explicar, historicamente, as abstrações e o tipo de perguntas próprio às ciências particulares, situando-se, assim, numa postura crítica em relação a elas. Numa palavra, o marxismo contém uma interpretação substancial do mundo enquanto situação com o auxílio de uma concepção histórico-filosófica que, certamente, se radica num projeto dogmático sobre o futuro, ${ }^{12}$ o que, para Apel, é o resultado da falta de uma reflexão crítica que tematize os pressupostos inelimináveis de nossos conhecimentos válidos. Para Apel, diante deste dilema a que chegou o pensamento dialético em sua formulação histórica depois de Hegel, o grande desafio teórico consiste em pôr criticamente em relação os dois momentos constitutivos da Dialética, ou seja, reflexão (a dimensão formal) e a práxis material (a dimensão do conteúdo).

9 Cf. Th. Litt, Hegel, Versuch einer kritischen Emeuenung, Heidelberg, 2. ed., 1961.

10 Apel aceita a reviravolta que $\mathrm{E}$. Tugendhat chama de "reflexiva" da filosofia moderna, que mudou fundamentalmente a estrutura do conhecimento filosófico, embora a interprete não num sentido analítico, mas transcendental. De agora em diante se impőe uma "divisão epistemológica de trabalho": todo e qualquer saber de conteúdo é o campo próprio das ciências particulares. A filosofia permanece com o universal: as condições inelimináveis de todo conhecimento de conteúdo. Cf. E. Tugendhat, Vorlesungen zur Einführung in die sprachanalytische Philosophie. Frankfurt am Main, 1976, p. 16.

11 Cf. K. O. Apel, Sprechaktetheorie und transzendentale Sprachpragmatik zur Frage ethischer Normen. In: K. O. APEL (org.). Sprachpragmatik und Philosophie. Frankfurt am Main, 1976, p. 15 e ss.

12 Para Apel, a modernidade do marxismo consiste no fato de ele ter refletido, numa perspetiva de filosofia social, o "utopismo implícito" da dinâmica do progresso tecnológico mundial, tendo-se posto, assim, numa perspectiva de um pensamento voltado para o futuro na medida em que, em vinculação com a técnica, ele elevou a utopia do homem novo a fim expresso da vida humana. Cf. K. $\mathrm{O}$. Apel, Der postkantische Universalismus in der Ethik im Lichte seiner aktuellen Missverständnisse. In: Diskurs und Verantwortung, op. cit., p. 180. 


\section{B - As raízes da Dialética no diálogo}

O desafio central, para Apel, no que diz respeito à Dialética hoje, consiste em pensar, positivamente, a essência da Dialética que permaneceu não pensada entre Hegel e Marx e nesta tarefa é, para Apel, muito importante o confronto com a filosofia hermenêutica ${ }^{13}$ articulada por H.-G. Gadamer, que, em contraposição ao criticismo dialético, conservou a pretensão substancial da dialética hegeliana enquanto um mediar-se do presente com sua tradição histórica, portanto, de uma forma diferente do marxismo. $\mathrm{O}$ que especifica a compreensão gadameriana da Dialética é que ele a interpreta a partir do diálogo ${ }^{14} \mathrm{e}$, assim, a situa no horizonte lingüístico do universo hermenêutico, o que, para Apel, é uma chance de desenvolvimento de uma filosofia Dialética autêntica e, por esta razão, ele escolhe o caminho da hermenêutica para enfrentar o que denomina o problema de uma dialética substancial da história.

O primeiro mérito da hermenêutica gadameriana é tentar trazer uma solução à questão filosófica central da Filosofia numa civilização tecnificada: o salvar a consistência própria das coisas na expressão de J. Hommes ${ }^{15}$ o ser-a-partir-de-si-mesmas das coisas frente ao "eros técnico" da modernidade e isto de uma forma que não se retorna à má metafísica no sentido de uma volta ao pensamento pré-moderno, pré-kantiano e pré-hegeliano, já que o ser próprio das coisas só pode ser tematizado enquanto linguagem das coisas em contraposição à postura objetivante das ciências modernas.

No entanto, para Apel, não podemos encontrar, na hermenêutica de Gadamer, uma solução para o problema da Dialética, pois Gadamer é incapaz de mediar a dimensão transcendental-reflexiva com a práxis material: sua filosofia hermenêutica conserva separados os dois momentos constitutivos da Dialética. No caso da hermenêutica de Dilthey a questão, para Apel, é muito simples uma vez que sua hermenêutica é, em última análise, uma hermenêutica da história do espírito, vinculada à concepção hegeliana da história enquanto autodesenvolvimento imanente do espírito. Nesta perspectiva, a crítica marxista das ideologias emerge como uma correção sistemática e historicamente necessária.

A questão se complica no caso da hermenêutica de Gadamer que não pretende ser uma hermenêutica da história do espírito, mas uma hermenêutica da história do ser, no horizonte aberto pela filosofia heideggeriana. Aqui, em contraposição a Dilthey, reaparece o problema da verdade na medida em que se tematiza a problemática da compreensão válida enquanto "produtividade do tempo" e não como autotransparência do espírito no sentido hegeliano. Isto significa dizer que Gadamer abre o espaço para uma mediação entre os conteúdos espirituais e a práxis contingente e material já que ele situa sua reflexão no horizonte lingüístico do uni-

Cf. K. O. Apel Szientistik, Hermeneutik und Ideolgiekritik, Entwurf einer Wissenschaftstheorie in erkenntnisanthropologischer Sicht. In: Transformation der Philosophie, v. 2, op. cit., p. 96-127.

14

Para Apel, a filosofia hermenêutica nos fez compreender que a existência de uma comunidade de comunicação é a pressuposição de todo conhecimento na dimensão sujeito-objeto enquanto metadimensão intersubjetiva da descrição objetiva e da explicação dos dados do mundo. Cf. K. O. Apel, op. cit., p. 114.

Cf. J. Hommes, Die Krise der Freiheit. Regensburg, 1958. 
verso hermenêutico, que implica uma corporificação fática e prática do espírito, o que o conduziu a interpretar a compreensão em sua historicidade originária. A historicidade emerge, aqui, como condição de possibilidade de toda compreensão de sentido.

A compreensão não é mais, aqui, simplesmente, a captação imediata de um conteúdo de sentido espiritual objetivo, mas a inserção do homem todo num evento de mediação de tradição através de que se supera a perspectiva de uma "filosofia do espírito". Para a possibilitação da compreensão não basta só, como pensava Dilthey, a reprodução intuitiva dos atos de vivência dos outros, uma vez que a fala está, sempre, vinculada ao comportamento prático dos falantes no mundo. Isto exige uma objetivação crítica da forma de vida prática dos outros. ${ }^{16}$

Na medida em que se pensa a linguagem como forma de vida histórica, emerge no seio mesmo da compreensão histórica a exigência de uma explicação crítico-ideológica do sentido, pois o espírito não entra, enquanto tal, diretamente, no tempo como sugere o idealismo, mas, sempre, através da mediação de uma história da natureza, que continua no comportamento social dos homens. ${ }^{17} \mathrm{Na}$ história compreensível do espírito se faz presente a história não compreensível da Natureza. Assim, os homens não são transparentes a si mesmos em suas intenções: até agora eles nem fizeram sua história sócio-política, nem suas conviç̧ões espirituais, como elas se depositaram em documentos lingüísticos, são pura expressão de suas intenções espirituais. Todos os resultados de suas intenções são, ao mesmo tempo, também, resultados de suas formas concretas de vida.

Por esta situação, que é produto da "condição humana" enquanto tal, a compreensão se choca com contradições, que não podem ser, simplesmente, trabalhadas com os métodos hermenêuticos, pois são provenientes da mútua imbricação do sentido e do não-sentido, de ações intencionadas e reações determinadas pela Natureza, que põem um limite à compreensão. Só a partir desta consciência seria possível articular uma filosofia hermenêutico-dialética capaz de levar em consideração o momento fático-contingente da mediação prático-material de todo sentido. Nesta perspectiva, para poder tematizar a unidade hermenêutica do sentido, que nós homens somos, este pensamento teria que empreender uma análise objetiva das condições não espirituais da constituição do sentido, o que, por sua vez, exige o uso de métodos que, para além da compreensão imediata, sejam capazes de trazer à tona o embate obscuro, estranho ao sentido, da facticidade material no mundo histórico. ${ }^{18}$

16 Pode ocorrer, segundo Apel, que os parceiros de uma conversa, gramaticalmente, se utilizem das mesmas palavras, mas não se entendam a partir de seu diferente lidar com o mundo, como, por exemplo, no caso de membros de diferentes classes sociais. Cf. K.-O. Apel, Reflexion und materielle Praxis, op. cit., p. 16.

17 Cf. K.-O. Apel, Szientistik, Hermeneutik, Ideologiekritik, op. cit., p. 121-122.

18 Para Apel, os fatores fáctico-contingentes da história humana precisamente porque não são transparentes como motivos, uma vez que eles são resultado de processos causais socialmente năo percebidos, mas, simplesmente, atuam, facticamente, na vida humana, precisam ser analisados com métodos de uma ciência explicativa quase-objetiva. Isto significa dizer, contra os pressupostos do idealismo, que a história humana não é puro produto de ações intencionais conscientes e responsáveis. Cf. K.-O. Apel, op. cit., p. 123. 
Do ponto de vista sistemático, o resultado do confronto com a filosofia hermenêutica significa a articulação da tarefa específica de uma filosofia dialética. Não se trata, simplesmente, como afirma, unilateralmente, o marxismo, da busca da mediação do sentido espiritual através da práxis material. Apel retoma as afirmações do jovem Marx sobre a superação da Filosofia através de sua realização e as interpreta como uma superação a ser efetivada por uma práxis que se inspira filosoficamente, o que, para ele, implica a justificação dialética de um programa de busca hermenêutica de pressupostos positivos ${ }^{19}$ do sentido da Antropologia e da Filosofia da História do marxismo. No contexto deste projeto teórico, a filosofia hermenêutica é a condição positiva da interpretação Dialética do sentido da história, que é, aqui, pensada como uma conversa continuada, contanto que ela se deixe mediar por seu complemento necessário: a crítica ideológica da práxis material. ${ }^{20}$

Para Apel, a hermenêutica de Gadamer não soube aproveitar as chances, nela implicitamente contidas, e a razão principal consiste na não-tematização das condições reflexivas da Dialética: ${ }^{21}$ a hermenêutica da história do ser deixa impensada a mediação efetiva entre consciência e práxis material na medida em que ela deixa fora de si a Dialética crítica do idealismo transcendental por não levantar a questão das condições de possibilidade da pretensão universal de validade de suas próprias sentenças. Neste sentido, a hermenêutica gadameriana é uma ontologia, que julga poder dispensar a reflexão noológica, ou seja, a reflexão transcendental, sobre os pressupostos inelimináveis de todo conhecimento e de toda ação, o que faz com que ela termine abandonando a idéia grega de uma ciência, universalmente, válida em função da inserção concreta na situação mundial do diálogo, agora válido para nós, e que nós homens somos em pertença histórica em nossas relações uns com os outros e em relação com o ser.

Neste debate, alguns elementos devem ficar claros segundo Apel. Assim, por exemplo, por um lado, uma orientação substancial no mundo, como a Dialética pretende oferecer, nunca pode ser válida universalmente e, por outro lado, uma Dialética formal, enquanto reflexão sobre os pressupostos do pensar, é válida intersubjetivamente, mas permanece impotente, porque destituída de conteúdo, frente a uma interpretação substancial do que é hoje. Se se reconhece isto e se se concebe a tarefa essencial da Dialética como a análise conteudal do sentido do mundo enquanto situação histórica, na medida em que a Dialética pretende ser filosofia e não profecia, ela precisa ser mediada por uma reflexão noológica enquanto explici-

19 O Apriori da comunidade ideal de comunicação como a pressuposição de qualquer argumentação científica, do qual pode ser deduzido aquele engajamento político e social, que constitui a medida valorativa suprema tanto para as ciências hermenêuticas da compreensão como para as ciências sociais criticas. Cf. K.-O. Apel, Wissenschaft als Emanzipation? Eine kritische Würdigung der Wissenschaftskonzeption der "Kritischen Theorie". In: Transformation der Philosophie 2, op. cit., p. 150.

Uma posição semelhante à de J. Habermas. Cf. J. Habermas, Zur Logik der Sozialwissenschaften, Frankfurt am Main, 1970, p. 71 e ss; Der Universalitätsanspruch der Hermeneutik. In: Hermeneutik und Dialektik I (ed. por R. Bubner/K. Cramer/R. Wiehl), Tübingen, 1970, p. 73-103. regulativo para a apropriação da razão na tradição, para a busca de um "aparecimento prévio da verdade", na expressão de E. Bloch, mesmo nos conteúdos ideológicos da tradição. Cf. K.-O. Apel, Wissenschaft als Emanzipation?, op: cit., p. 150. 
tação das condições lingüístico-comunicativas da constituição e da validade intersubjetiva do conhecimento dos objetos do mundo.

Nem a filosofia hermenêutica, nem o marxismo conseguem efetivar a tarefa específica da dialética. O materialismo dialético, não sendo mais capaz de provocar uma superação do dogmatismo na interpretação marxiana da História através de uma reflexão transcendental, se transformou numa dogmática objetivo-metafísica no sentido pré-kantiano, o que é o resultado da absolutização do momento material e do esquecimento total do momento ideal do conhecimento humano. ${ }^{22} \mathrm{O}$ engano central do materialismo do marxismo ortodoxo consiste, precisamente, no esquecimento do momento subjetivo da práxis.

Para Hegel, a reflexão Dialética não tem a coisa fora de si mesma, como é o caso na racionalidade própria às ciências modernas, uma vez que, para ele, a Dialética é uma reflexão que é, igualmente, um saber de conteúdos, isto é, uma ontologia. Não é sem riscos, segundo Apel, que se leve esta exigência hegeliana até o ponto em que se possa esquecer que o homem finito, mesmo em sua mais profunda ligação com a coisa, ao mesmo tempo, tem que sustentar sua interpretação no ponto da abstração mais formal, simplesmente, porque, para ele, na situação, forma e conteúdo do mundo, orientação universal e concreta, nunca podem simplesmente coincidir. Para Hegel isto acontecia, precisamente, no saber "absoluto" que implica, exatamente, a identificação especulativa da Dialética do conceito com o movimento da coisa.

Na medida em que se pensa Dialética a partir da "situação finita", a postura hegeliana pode ser lida como antecipação da teoria materialista do reflexo de Lênin, que, nesta perspectiva, se revela como uma redução materialista e referida à situação, da doutrina hegeliana da reflexão absoluta, portanto, do objetivismo metafísico. Lênin, segundo Apel, não percebeu que rejeitar a postura da reflexão absoluta implica liberar, de sua mediação total com a coisa, o momento abstrato da reflexão da consciência enquanto uma regulação autônoma do conhecimento. Já que a teoria do conhecimento do materialismo dialético não reconhece, como uma contra-instância independente do processo material, a transcendência formal, que é sempre possível, da consciência universalmente válida, enquanto tal, para além da auto-interpretação perspectivística da coisa na situação histórica, ela não consegue contrapor-se, filosoficamente, à dogmatização de sua Filosofia da História.

\section{$C$ - A Dialética como relação entre reflexão e práxis}

Para Apel, a determinação do que seja, propriamente, Dialética é o resultado da compreensão de duas questões fundamentais: 1) Uma interpretação substancial do mundo enquanto situação histórica, se pretende evitar o dogmatismo, precisa mediar-se por uma reflexão transcendental; 2) A consciência reflexiva do homem só alcança conteúdo através da mediação da práxis corporal, através do contato

22 Que, explicitado através de uma reflexão transcendental, forneceria às ciências socias críticas um critério para detectar, nas alienaçōes institucionais, as formas e os conteúdos de uma falsa consciência, determinados por interesses limitados de classes e que constituem obstáculos para a realização da comunidade ideal de comunicação na situação histórica específica. Cf. K.-O. Apel, op. cit., p. 151. 
material do homem com o mundo. Há uma relação de complementaridade entre o que Apel denomina "apriori-corpo" (engajamento corporal) e o "apriori-consciência" (reflexão), ou seja, ambas as condições de possibilidade se complementam necessariamente, embora na efetivação de um ato específico de conhecimento uma das dimensões possa assumir a primazia: toda experiência é, primariamente, conhecimento através do engajamento corporal, toda formação teórica é, primariamente, conhecimento através da reflexão. ${ }^{23}$ Articular o sentido da Dialética, para Apel, significa compreender como é possível a mediação da consciência através da práxis, 0 que pode ocorrer na medida em que se toma a linguagem como ponto de partida, uma vez que, na linguagem enquanto efetividade imediata do pensamento, segundo a expressão de Marx na ideologia alemã, acontece, no nível mais alto, a mediação da consciência através da práxis interventora do homem no mundo.

A compreensão apeliana da Dialética depende, fundamentalmente, de sua compreensão da linguagem enquanto movimento recíproco de mediação. Os sinais da linguagem são, enquanto fenômenos em oposição paradigmática, já antes de seu uso atual, mediados pelas possíveis intenções de sentido, mas, por sua vez, as intenções humanas de sentido, enquanto vinculadas à linguagem, são mediadas, já antes de sua atualização, por modelos de articulação acoplados a sinais. Numa palavra, o apriori-corpo do conhecimento se mostra, aqui, precisamente, no fato da vinculação da manifestação intersubjetiva de sentido a uma expressão, sensivelmente perceptível.

É precisamente enquanto movimento recíproco de mediação que a linguagem, em Marx, em perfeita consonância com Hegel, é a consciência prática, existente, também, para os outros homens e, também, para mim mesmo, enquanto consciência efetiva. Se nosso pensamento, no que diz respeito à determinidade do sentido depende da linguagem, então, a Dialética, enquanto articulação do pensamento, já é, sempre mediada através da práxis corporal. Ela não deve, portanto, seu conteúdo e a força do negativo como antítese à força mágica de uma reflexão, sempre possível, enquanto negação, mas, antes, à visão prévia de uma alternativa do sentido lingüístico.

Para Apel, o confronto com a hermenêutica nos ensina ainda mais: a linguagem do diálogo não é só enquanto tal mediação prático-corporal do pensamento, ${ }^{24}$ mas tem, também, sempre, enquanto linguagem-uso, que mediar seus componentes semânticos através da práxis comportamental de um grupo social. Um novo movimento recíproco de mediação emerge aqui: por um lado, a práxis humana, enquanto não é orientada por instintos, tem que ser mediada através da emergência eidética de um sentido na consciência. Por outro lado, nenhum sentido gramatical

23 Para Apel, as condições de possibilidade e validade do conhecimento não podem ser reduzidas a funções lógicas da consciência. Para se chegar a uma constituição de sentido, a consciência tem que engajar-se corporalmente no aqui e agora. Assim, toda experiência do mundo pressupõe, como sua condiçăo de possibilidade, um engajamento mundano corporal, que se determina como intervenção instrumental na natureza. É isto o que Apel denomina o apriori-corpo: os sinais da linguagem, os orgãos dos sentidos e os instrumentos técnicos não são objetos de conhecimento, mas antes condições de possibilidade de qualquer constituição de sentido. Cf. K.-O. Apel, Szientistik, Hermeneutik, Ideologiekritik, op. cit., p. 96-99.

24 A forma específica do engajamento corporal de nosso conhecimento corresponde a um interesse determinado de conhecimento. 
se deixa explicitar na evidência da consciência de uma forma puramente fenomenológico-eidética, numa palavra, a signifiçação permanece atrelada à sua constituição, contingente e eideticamente obscura, numa práxis comportamental socialmente consolidada. ${ }^{25}$

A conseqüência última de toda esta reflexão, para Apel, é que a Dialética, com a linguagem, é mediada através do engajamento material-prático dos homens no trabalho, no amor, no jogo e na luta, o que implica que toda interpretação Dialética de sentido, já, contém em si, sempre, uma tomada de posição em relação ao mundo no que diz respeito a uma futura práxis. Para Apel, aqui está a explicação por que Hegel transforma a simples alteridade, teoreticamente demonstrável dos fenômenos, em antítese: não se trata, simplesmente, da onipotência da reflexão, mas do fato de que na interpretação Dialética do mundo está, sempre, implícita, a tomada de posição do homem, que tem que enfrentar, praticamente, uma situação. ${ }^{26}$

Para Apel, em princípio é indiferente se se pensa a Dialética como subjetiva, ou seja, como a possibilidade do homem de posicionar-se, alternativamente, em relação a sua futura práxis, ou objetiva, ou seja, como estrutura antitética das próprias coisas, pois em ambos os casos se realiza a estrutura dialética dos fenômenos do sentido enquanto estrutura de uma virtual interpretação lingüística do mundo enquanto situação. A dialética subjetiva pressupõe minha pertença à natureza, enquanto que, no caso da dialética objetiva, a leitura do processo real enquanto processo dialético não pode acontecer sem a reflexão do homem. É possível, por isto pensar numa passagem entre ambas as dialéticas, ou seja, entre a dialética objetiva das relações que, no futuro, devem continuar a partir do homem e a dialética subjetiva das possibilidades humanas que têm, no contexto objetivo, suas condições de possibilidade. A passagem se realiza, precisamente, em sua concepção da História de acordo com a fórmula do jovem Marx: humanização da natureza e naturalização do homem.

A dialética destes momentos pode ser rompida na medida em que se absolutiza um dos momentos deixando desaparecer o outro. Assim, por exemplo, a dialética existencialista da subjetividade parte do caso limite de uma dialética subjetiva e absolutiza a decisão sobre possibilidades, convertendo-a num fim em si mesmo irracional frente ao jogar-se abstrato na historicidade da situação enquanto tal. Por outro lado, no materialismo histórico dogmático, a dialética objetiva absorve a prática subjetiva. Para Apel, ambas as posições não passam de totalizações de casos limites da Dialética, formas decadentes de uma dialética aquém do idealismo e do materialismo, do subjetivismo e do objetivismo. Dialética, entendida como lógica filosófica da situação, tem que, para Apel, captar a tensão entre seus dois elementos básicos: a reflexão voltada para o mundo e o engajamento prático material no mundo.

25 Para Apel, não só cada constituição individual de um possível sentido é mediada por um engajamento corporal da consciência cognoscente, mas, também, a validade intersubjetiva de qualquer constituição de sentido. Cf. K.-O. Apel, op. cit., p. 98.

26 Para Apel, é, precisamente, este engajamento material no mundo vinculado a interesses, que distingue uma fenomonologia teorética no estilo de Husserl de uma fenomenologia dialética da experiência histórica. Cf. K.-O. Apel, op. cit., p. 25-26. 


\section{II - A Filosofia enquanto ontologia dialética mediada transcendental-pragmaticamente}

\section{A - A concepção nominalista da fundamentação última}

Para K.-O. Apel a Filosofia, hoje, tem de levar a sério a reviravolta lingüísticopragmática do pensamento e, enquanto tal, sua primeira tarefa é o confronto com uma das conseqüências possíveis desta reviravolta: a destranscendentalização, como um dos traços característicos do pensamento contemporâneo e que, para ele, em última análise, significa a negação, enquanto tal, da tarefa própria à Filosofia e sua redução à racionalidade específica das ciências. ${ }^{27} \mathrm{Na}$ realidade, esta situação ajuda a clarificar o específico do discurso filosófico em contraposição a todos os outros discursos da linguagem humana: a tematização das condições intranscendíveis de todo discurso humano, ${ }^{28}$ uma vez que a reviravolta lingüístico-pragmática demonstrou que a linguagem é o "medium" intranscendível de todo sentido."

Ele se situa, portanto, dentro da reviravolta de pensar aberta por Kant: não compete à Filosofia o conhecimento dos objetos de nossa experiência, portanto dos conteúdos, mas sua tarefa própria é a questão da validade destes conhecimentos, ou seja, trata-se de levantar a questão dos critérios, da medida última, das regras e dos procedimentos para se estabelecer a validade dos nossos conhecimentos. Numa palavra, Filosofia é, essencialmente, fundamentação, mais radicalmente ainda, fundamentação última já que tematização das condições últimas de possibilidade da constituição e da validade de todo sentido.

A radicalidade do ceticismo contemporâneo levou a filosofia transcendental, também, a um rigor maior na articulação de seus procedimentos. Assim, para Apel, a fundamentação última não pode articular-se na forma de um júzo condicional, hipotético, como é típico da racionalidade das ciências empíricas, mas seu específico consiste, precisamente, na articulação de uma demonstração "não condicional" e isto só é possível na medida em que o transcendental não é mais visto, simplesmente, como condição de possibilidade da experiência que, em princípio, o cético, sempre pode pôr em dúvida, mas, precisamente, como condição necessária de possibilidade de toda argumentação, inclusive da do cético de tal modo que sua negação explícita no nível do conteúdo expresso (nível semântico) da proposição implica sua reposição a nível pragmático. ${ }^{30}$

27 Como o conhecimento científico se entende, hoje, como conhecimento hipotético-dedutivo de fenômenos, ele se autocompreende como conhecimento de conteúdos enquanto conhecimento de objetos e eventos em seu comportamento e não como conhecimento de essências. Enquanto conhecimento dedutivo, conhecimento cuja fundamentação é, essencialmente condicional, o que significa dizer que não há nenhuma proposiçăo universalíssima que seja verdadeira, isto é, válida para todos os sub-sistemas da realidade.

0 que significa afirmar que o próprio principio do falibilismo, enquanto expressão da racionalidade das ciências, precisa de uma fundamentação filosófica última. Cf. K.-O. Apel, Fundamentação última não-metafisica?, op. cit., p. 313.

Duas descobertas são fundamentais para a "transformação semiótica", como diz Apel, da filosofia transcendental: 1) a descoberta da linguagem como medium de todo sentido; 2) a descoberta de que a pragmática é a dimensão essencial da linguagem, ou seja, da estrutura proprosicional-performativa da linguagem. Cf. F. J. Herrero, Sujeito e ética. In: Kriterion 88 (1993) 93. 
Numa palavra, o que propriamente pretende a pragmática transcendental não é abandonar a reflexão transcendental, mas, ao contrário, transformar sua estrutura e, com isto, radicalizá-la a partir da reviravolta lingüístico-pragmática do pensar, ${ }^{31}$ o que vai tornar possível a superação da famosa objeção de circularidade ${ }^{32}$ feita à filosofia transcendental na forma em que Kant a articulou: ele toma como fundamento de validade das sentenças sintéticas a priori a possibilidade da experiência, quando são justamente estas sentenças que possibilitam a experiência.

Ora, a própria axiomatização da Matemática e de boa parte da Física, em nosso século, levou a um desenvolvimento pleno da demonstração dedutiva (conhecimento por derivação de algo a partir de algo), o que tornou mais aguda a pergunta pela especificidade da demonstração filosófica enquanto fundamentação última em sua diferença com o ideal metodológico das ciências modernas da natureza, como também com as ciências da interpretação do sentido expresso em obras históricas A partir daqui, emerge a filosofia como retorno reflexivo às condições de validade da argumentação: ${ }^{33}$ trata-se de atingir algo que, em princípio, não pode ser atingido pela dúvida, pois é sua própria condição de possibilidade, isto é, que não pode ser negado sem que a dúvida se destrua a si mesma e que, por outro lado, não pode ser demonstrado através da demonstração dedutiva, porque é sua condição de possibilidade. Filosofia é, assim, radicalização da dúvida, pois é tematização do princípio que torna a própria dúvida possível.

W. Kuhlmann ${ }^{34}$ tentou articular com todo rigor o cerne do argumento transcendental-pragmático: trata-se de demonstrar, de acordo com a reviravolta lingüísticopragmática, o caráter ineliminável da argumentação sensata, ou seja, vale aprioricamente como verdadeiro o que é pressuposto em qualquer argumentação, o que se pode estabelecer através das seguintes sentenças: "1) Não podemos sensatamente, isto é, sem cairmos em contradição conosco mesmos, recusar as regras e as pressuposições da argumentação sensata; 2) Não podemos, sem petitio principii, fundamentar estas regras e pressuposições; 3) Não nos podemos decidir, sensatamente contra seu reconhecimento sem pressupô-las pelo menos implicitamente. Numa palavra, nós já sempre e necessariamente reconhecemos estas regras que escapam a qualquer dúvida" ${ }^{35} \mathrm{O}$ procedimento argumentativo, aqui, é rigorosamente reflexivo: ele se centra sobre aquilo que implícita e necessariamente pressupomos quando fazemos estes proferimentos, portanto, tematizamos via contradição pragmática as condiçőes necessárias de nossa ação lingüística.

31 que implica refletir, transcendentalmente, não a partir da consciência, portanto, da subjetividade, mas da linguagem, ou seja, da intersubjetividade lingüisticamente mediada.

Ela não considera, por isso, estas condições como um objeto, no estilo das ciências, mas, precisamente, numa reflexão estrita, como condiçāo irrecusável de validade da ação lingüística enquanto tal. Cf. W. Kuhlmann, Reflexive Letzbegründung. Untersuchungen zur Transzendentalpragmatik. Freiburg/München, 1985, p. 76 e ss.

34 Cf. W. Kuhlmann, op.cit., p. 82.

35 Cf. M. A. de Oliveira, Sobre a Fundamentação, op. cit. p. 81-82. 
A pragmática transcendental se põe, assim, numa longa tradição no pensamento ocidental ${ }^{36}$ - a dúvida, posta radicalmente, se transforma em certeza - e a reinterpreta a partir da contraposição entre a dimensão semântica e a dimensão pragmática da linguagem. $\mathrm{O}$ cerne do argumento pode ser exposto à moda dos dialéticos com tese, antítese e síntese. Partimos de uma proposição universal afirmativa: todas as proposições universalíssimas são verdadeiras. Com esta proposição se afirma, num primeiro momento, de forma tética, que há uma razão oniabrangente, universalíssima.

No entanto, como, em todo proferimento, há uma pretensão de exprimir a determinação plena ${ }^{37}$ daquilo sobre que falamos, isto é, pragmaticamente sempre antecipamos a determinação plena, semanticamente, porém, aqui, não se explicita esta determinação completa. A sentença pressupõe mais (pragmaticamente) do que ela é capaz de afirmar explicitamente (semanticamente) de tal modo que há um descompasso entre a antecipação pragmática e a expressão semântica, portanto, uma contradição pragmática que revela que a proposição é falsa, uma vez que ela só seria verdadeira se pudesse exprimir, explicitamente, tudo o que pressupõe.

A proposição cética fundamental por sua vez - não há nenhuma proposição universalíssima que seja verdadeira - como antítese, se contrapõe à nossa primeira proposição na forma de contrariedade ${ }^{38} \mathrm{e}$, precisamente, enquanto ato de fala, isto é, ao ser proferida, desdiz, a nível pragmático, ${ }^{39} 0$ que é dito a nível semântico: quem a enuncia, por seu ato de fala, levanta a pretensão de dizer algo que é, assim, como está sendo dito, ou seja, quem duvida, afirma, implicitamente, ${ }^{40}$ algo, o que revela a proposição cética como, logicamente, insustentável. ${ }^{41}$

Está em jogo, aqui, uma expressão lingüística auto-reflexiva e negativa que, na medida em que reflete sobre si e se aplica a si mesma, se autodestrói logicamente, donde se conclui pelo menos, num primeiro momento, de acordo com as leis de inferência, as regras da lógica formal, como os antigos as articularam, que $\mathrm{s}$ e u cont

36 Cf. Agostinho, De vera religione, 39 e 73; De Thinitate X, 10 e 14. R. Descartes, Meditationes de prima philosophia. In: Oeuvres philosophiques (1638-1642), Tomo II, Paris, 1967, Meditatio Prima, p. 177 e ss.

37 Cf. W. Wieland, Bemerkungen zum Anfang von Hegels Logik. In: R. P. HORSTMANN (hrsg), Seminar: Dialektik in der Philosophie Hegels, Frankfurt am Main, 1978, p. 194-212. V. Hösle, Hegelssystem. Der Idealismus der Subjektivität und das Problem der Intersubjektivität. v. 1, Hamburg, 1988, p. 198-210.

38 De acordo com as regras da lógica formal para formar a proposição contrária basta pôr a negação e não alterar o quantificador.

39 O que manifesta que a demonstração filosófica não se faz como dedução lógico-formal, mas a filosofia trabalha com a contraposição entre a dimensão semântica e a dimensão pragmática, isto é, tem na contradição pragmática a mediação necessária para realizar sua tarefa de tematizar as condições necessárias de todo sentido, isto é, expresso na liguagem da filosofia dos gregos, para "demonstrar" os princípios últimos.

40 Cf. W. Kuhlmann, op. cit. p. 73. D. Böhler, Rekonstruktive Pragmatik. Von der Bewusstseinsphilosophie zur Kommunikationsreflexion: Neubegründung der praktischen Wissenschaften und Philosophie, Frankfurt am Main, 1985, p. 360.

41 Cf. W. Khler, Zur Debatte um reflexive Argumente in der neueren deutschen Philosophie. In: Philosophie und Begründung, op. cit., p. 303-333. 
raditório é verdadeiro, ou seja, que há, pelo menos, algumas proposições universalíssimas que são verdadeiras. Na sintaxe dos analíticos, pode-se exprimir o cerne do argumento transcendental-pragmático, logicamente, assim: "ao dizer que nenhuma proposição é verdadeira, esta proposição universalíssima se flecte sobre si mesma e, ao assim fazer, implode, porque ela mesma continua com a pretensão de ser verdadeira, embora afirme que todas as proposições são falsas. Se ela é verdadeira, então ela é falsa; para ser verdadeira, ela precisa ser falsa". ${ }^{42}$ Esta primeira síntese já é suficiente para a refutação do cético, o que constitui o núcleo duro do argumento da pragmática transcendental e, portanto, da Filosofia, enquanto tal, enquanto retorno reflexivo aos pressupostos necessários do discurso humano.

No jogo de opostos, que podemos usar, aqui, para traduzir a intenção do argumento da pragmática transcendental, temos duas proposições contrárias, uma afirmativa (todas as proposiçōes universalíssimas são verdadeiras) e outra negativa (não há nenhuma proposição universalíssima que seja verdadeira), uma primeira síntese, que é mediada pela falsidade da antítese, expressa em linguagem analítica, é uma proposição particular afirmativa - pelo menos algumas proposições universalíssimas são verdadeiras - que se revela, aqui, através da mediação de uma reflexão transcendental, como um princípio universal, ${ }^{43}$ já que se algumas proposições são verdadeiras, a verdade em princípio existe o que significa dizer que a pressuposição pragmática da verdade é condição de possibilidade do próprio ceticismo, o que o revela como insustentável. "As "Assim, os pressupostos da argumentação sensata não podem ser negados sem contradição nem podem ser fundamentados por derivação sem petitio principii, isto é, sem pressupor sua validade". . $^{45}$

Numa palavra, a pragmática transcendental tem seu grande mérito na legitimação do jogo de linguagem próprio à Filosofia e em ter explicitado sua estrutura: trata-se de uma demonstração não por mediação da derivação, pois, neste caso, seria impossível uma fundamentação última, mas por reflexão estrita através da mediação da contradição pragmática, o que torna possível a explicitação dos pressupostos irrecusáveis do conhecimento lingüisticamente mediado.

42 Cf. C. R. V. Cirne Lima, "Sobre a contradição pragmática como fundamentação do sistema". In: Síntese Nova Fase 55 (1991) p. 599.

43 A passagem da proposição afirmativa particular para o princípio universal não se faz por inferência lógico-formal, que não seria possível, mas por reflexäo transcendental sqbre as condições de possibilidade: do fato demonstrado pela mediação da contradição pragmática de que, pelo menos algumas proposições são verdadeiras, se pressupōe, como sua condição necessária de possibildade, que proposiç̋̄es em princípio podem ser verdadeiras. Cf. C. R. V. Cime Lima, op. cit. p. 600.

44 O cerne da argumentação da pragmática transcendental foi apresentada, aqui, seguindo a formulação de Cime Lima, em forma dialética, isto é, na forma de um jogo de opostos com tese, antítese e síntese, expressas em sintaxe analítica, isto é, em proposiçöes bem construídas. Isto mostra que, pelo menos do ponto de vista da estrutura lógica da argumentação, há uma imbricação entre método transcendental e método dialético. Na verdade, a passagem da proposiçăo univerșal negativa para a verdade da proposição particular afirmativa, como seu contraditório, se faz de acordo com as regras clássicas da lógica formal de modo que, aqui, se revela uma "unidade na diferença" entre lógica formal, transcendental e dialética.

45 Cf. M. A. de Oliveira, Sobre a Fundamentação, Porto Alegre, 1993, p. 75. 
Retomando a sintaxe típica dos dialéticos, onde o sujeito lógico das proposições é sempre universal, ${ }^{46}$ podemos construir um segunda síntese, agora no sentido estrito do jogo de opostos, ou seja, explicitar um nível superior que seja capaz de conter os outros dois como verdades parciais: ${ }^{47}$ todas as proposições ou são verdadeiras ou falsas. Nosso argumento utilizou as regras clássicas da lógica formal (na construção da proposição contrária como antítese e na refutação da proposição cética), o procedimento reflexivo dos transcendentais (passando da primeira síntese para o princípio universal - existe verdade - como sua condição de possibilidade) e foi exposto na estrutura dialética do jogo de opostos, com duas sínteses: uma conseguida de acordo com a regra lógica da formação da proposição contraditória (já suficiente para a refutação do cético). Com isto se mostra a co-originariedade da lógica formal, transcendental e dialética. ${ }^{48} \mathrm{O}$ núcleo duro do pensamento filosófico se revela, assim, a unidade e a diferença do formal, do transcendental e do dialético.

A pragmática-transcendental se articula a partir da mudança de paradigma que se articulou como reviravolta lingǘrstico-pragmática do pensar. Isto significa dizer que o princípio-fundamento de toda ação lingüística não é mais, como na filosofia transcendental a partir de Kant, uma estrutura subjetiva, mas, precisamente, intersubjetiva. No entanto, seu apriori continua nominalista: não tem relevância ontológica. Para Apel, a fundamentação última "não fornece, portanto, nenhuma explicação ontológica do mundo, mas apenas uma autocertificação da razão argumentativa". ${ }^{49}$ Isto significa dizer que se conserva a contraposição moderna entre 0 ideal e o real, o formal e o conteudal, ou seja, numa palavra, se repõe, numa interpretação transcendental-pragmática, a contraposição nominalista entre o simplesmente singular, enquanto real e concreto, e o universal, enquanto ideal e abstrato. ${ }^{50}$ É precisamente isto que faz com que Apel vá buscar, fora da reflexão filosófica, isto é, na práxis material, o conteúdo que este paradigma de filosofia, por definição, não pode dar.

\section{$B$ - A concepção ontológica da fundamentação última}

No debate contemporâneo sobre a especificidade do "jogo de linguagem" da Filosofia, o que separa, de fato, transcendentais-pragmáticos e dialéticos não é,

46 C. R. V. Cime Lima, "A Lógica do Absoluto". In: Sintese Nova Fase 63(1991) p. 511. "[...] o sujeito lógico, sempre pressuposto pela dialética e quase nunca nela expresso, é a totalidade [...]".

47 A unidade dos opostos na linguagem dos antigos.

48 Normalmente, os dialéticos não trabalham com proposições bem construídas, no sentido aristotéli$\mathrm{co}$, isto é, com sujeito, predicado e cópula, mas com o "jogo de opostos", onde aparecem idéias em oposição, que podem chegar ou não a uma unidade mais alta. O que se fez, aqui, foi uma espécie de tradução do jogo de opostos na sintaxe analítica. Cf. C. R. V. Cirne Lima, A lógica do Absoluto, op. cit., p. 501-506.

49 Cf. K.-O. Apel, Fundamentação última não-metafísica, op. cit., p. 317.

50 Cf. E. Heintel, Die beiden Labyrinthe der Philosophie. Systemtheoretische Betrachtungen zur Fundamentalphilosophie des abendländischen Denkens. v. 1. Wien/München, 1968, p. 115 e ss; Grundriss der Dialektik, v. 1, Zwischen Wissenschaftstheorie und Theologie, Darmstadt, 1984, p. 226-235. 
propriamente, o caráter transcendental ou não do pensamento filosófico, uma vez que, para os dialéticos, Filosofia é, pelo menos num primeiro momento, embora não exclusivamente, fundamentação última do pensamento e enquanto tal retorno reflexivo do pensamento sobre si mesmo e sobre seus pressupostos inelimináveis. O princípio último da Filosofia é, assim, para a Dialética, desde Platão, o pensamento do pensamento. ${ }^{51} \mathrm{~A}$ questão decisiva, aqui, é a maneira de entender a fundamentação última e as conseqüências daí decorrentes para a natureza da reflexão filosófica.

A questão central, neste contexto, é que, para a Dialética, Filosofia é uma ontologia transcendental-pragmaticamente mediada, ou seja, para o pensamento dialético a estrutura pensamento do pensamento não é algo, simplesmente, subjetivo ou intersubjetivo, pressuposto, assim, somente pelo pensamento finito do ser humano, mas algo objetivamente existente, portanto, pressuposto por todo ser. ${ }^{52}$ Para V. Hösle, ${ }^{53}$ por exemplo, é da mais alta importância, para a compreensão do que faz, propriamente a Filosofia, que a pragmática-transcendental tenha renovado, a partir da reviravolta lingüístico-pragmática, a idéia de que sentenças absolutas (de fundamentação última), só podem ser demonstradas indiretamente, ou seja, a partir da implosão da posição contraposta, o que significa dizer que os primeiros princípios só podem ser demonstrados através de uma prova indireta, ou seja, pela mediação de uma contradição dialética. Esta é, aliás, a única forma de superação de uma filosofia dogmática que, em última instância, estabelece os primeiros princípios por intuição e não por argumentação, como foi o caso na ontologia aristotélica em sua longa influência no pensamento da tradição ocidental.

A novidade da concepção apeliana, para Hösle, está na distinção entre contradição semântica e contradição pragmática, o que é fundamental inclusive para que se compreenda que a Dialética, em nenhum momento, põe em questão a validade do princípio de não-contradição, ${ }^{54}$ pois ela não trabalha com contradições semânticas e sim com contradições pragmáticas. No entanto, para Hösle, ${ }^{55}$ é importante chamar atenção para o fato de que nem toda contradição pragmática interessa à Filosofia, porque há contradições pragmáticas que são, somente, empíricas e nestes casos a contradição pode, em princípio, ser eliminada. Há, no entanto, contradições pragmáticas que, em quaisquer circunstâncias, permanecem contraditórias. Estas são, propriamente, contradições dialéticas e constituem o núcleo duro do argumento de fundamentação última. direção de um projeto de sistema, de uma teoria abrangente e universal. Cf. C. R. V. Cirne Lima, "A Lógica do Absoluto". In: Síntese Nova Fase 63(1993)508. matik, Letzbegründung, Ethik. München, 1990, p. 160 e ss.

54 A objeção que já vem de Aristóteles, retomada, em nosso século, por K. Popper. Cf. K. Popper, Was ist Dialektik? In: Logik der Sozialwissenschaften. 9. ed., Köln, 1976, p. 262-290. 
Para Hösle, a relevância ontológica da estrutura explicitada pela mediação da contradição pragmática decorre, imediatamente, do próprio sentido da fundamentação última: contrapor esta estrutura a algo diferente dela seria contraditório ao sentido de fundamentação última, pois se explicitamos uma estrutura necessária a qualquer discurso com pretensão de validade, nada podemos pensar fora desta estrutura, ${ }^{56}$ o que significa dizer que a estrutura pensamento do pensamento é, também, uma determinação ontológica, numa palavra, as verdades aprióricas (do pensar e do falar) são também verdades ontológicas (dos seres).

No horizonte aberto por Hösle, Cirne Lima ${ }^{57}$ radicaliza a argumentação na intenção de apresentar a Dialética como a conciliação do ideal (transcendental) e do empírico (ontológico) de tal maneira que se possa superar tanto uma concepção puramente formal (nominalista) da fundamentação última, como uma concepção não transcendental (realista) da Ontologia. O ponto de partida é a contradição dialética, como Hösle a definiu: proposições auto-reflexivas negativas que, sendo individuais e empíricas, são sempre e necessariamente, contraditórias. Neste caso, já se revela a imbricação do contingente e do necessário: algo contingente suporta algo não contingente. Numa palavra, aqui se dá uma passagem pela mediação da contradição pragmática, do individual, empírico e contingente para o universal, transcendental e necessário.

O passo lógico seguinte é a passagem de proposições auto-reflexivas negativas individuais e empíricas para proposições auto-reflexivas negativas universais como a proposição do cético: nenhuma proposição universalíssima é verdadeira. Também esta proposição é igualmente individual, empírica e contingente, pois se trata de uma proposição determinada, proferida numa língua específica num determinado momento por um sujeito determinado e universal, transcendental e necessária, pois a implosão lógica se dá necessariamente, sejam quais forem os falantes e as circunstâncias de seu proferimento. O pragmático, que é individual, empírico e contingente, aqui se torna universal, transcendental e necessário, que vale sempre e para todos.

Este procedimento nos revela, para Cirne Lima, a natureza da Filosofia: a conciliação, em última instância, entre o transcendentalismo idealista e o empiricismo de uma realidade contingente. Tarefa primeira da reflexão filosófica é a tematiza-

56 Para Hösle, é contraditório afirmar que há conhecimentos aprióricos não-hipotéticos e que, conseqüentemente, temos que pensar a partir dessas leis, o que é o resultado da fundamentação última e, ao mesmo tempo, dizer que esta estrutura nada tem a ver com a realidade, pois reconhecer o caráter irrecusável desta estrutura significa dizer que nada podemos conhecer fora desta estrutura. Como podemos falar de realidade a não ser a partir desta estrutura? Numa palavra, quem fala das leis do pensar e das leis da realidade e diz que elas são completamente diversas, comete uma contradição performativa. Cf. V. Hösle, Begründungsfragen des objektiven Idealismus. In: Philosophie und Begrïndung, ed. por Forum f. Phil Bad Homburg, Frankfurt am Main, 1987, p. 249.

Cf. C. R. V. Cime Lima, Sobre a contradiçäo pragmática como fundamentação do sistema, op. cit., p. 609 e ss. Cime Lima concorda com Hösle em que o sistema filosófico a ser aceito é o idealismo objetivo. No entanto, acha que a demonstração apresentada por Hösle não consegue provar que todas as grandes leis do pensar sejam, também leis do ser. Daí o sentido da radicalização do argumento. Cf. C. R. V. Cirne Lima, op. cit., p. 606-607. 
ção dos principios universalíssimos que, enquanto tais, são auto-referentes. Sua demonstração se dá pela mediação da contradição pragmática nas proposições universalíssimas, auto-referentes negativas. Contra toda uma corrente, hoje, que vê na antinomia o cerne da Dialética, ${ }^{58}$ Cirne Lima defende a idéia de que a contradição pragmática não é uma antinomia estrita e sim uma contradição potenciada. No caso de uma antinomia estrita, quando uma proposição é verdadeira, ela é falsa e quando ela é falsa, ela é verdadeira. ${ }^{59} \mathrm{~A}$ diferença fundamental entre a antinomia $\mathrm{e}$ a contradição pragmática é que "a antinomia estrita implode logicamente, sim, mas a implosão aqui é diferente daquela que ocorre na contradição pragmática", ${ }^{60}$ pois na antinomia há um oscilar ad infinitum entre verdade e falsidade, mas esta implosão $^{61}$ não remete, diretamente, para uma verdade que lhe seja contraditória, ${ }^{62}$ como é o caso na contradição pragmática. Numa palavra, para Cirne Lima, há uma assimetria de estrutura entre a antinomia estrita e 0 argumento dialético de fundamentação última, uma vez que neste desaparece a oscilação ao infinito entre verdade $e$ falsidade.

Na proposição cética - nenhuma proposição é verdadeira - na medida em que ela é proferida, não há uma oscilação entre verdade e falsidade, mas a grande implosão lógica que conduz para a verdade da proposição contraditória - há, pelo menos, algumas proposições verdadeiras - donde se chega, por uma reflexão transcendental, à proposição: há, em princípio, proposições verdadeiras. Para Cirne Lima é exatamente aqui o ponto em que se faz a superação de uma reflexão transcendental, puramente formal, pois, neste procedimento, se revela a imbricação entre o ideal (transcendental) e o empírico (ontológico). Trata-se de uma existência, de algo que é tanto razão, como existência. A razão se revela como um fato ineliminável, pois qualquer tentativa de sua negação a repõe.

No cerne mesmo da contradição pragmática, o indivíduo se torna universal, o contingente, necessário e o empírico, transcendental. Estamos, a rigor, não mais num idealismo subjetivo ${ }^{63}$ na forma da filosofia transcendental formulada por Kant e transformada, semioticamente, por Apel, que ainda permanece numa reflexão formal de tal modo que o conteúdo é buscado para além da reflexão no engajamento prático-material dos homens no trabalho, no amor, no jogo e na luta, o que

58

59 que e 0 o e da objetividade e permanece na subjetividade como a determinação última afirmativa enquanto tal. Cf. G. W. F. Hegel, Enzyklopädie der philosophischen Wissenschaften im Grundrisse (1830), ed. por F. Nicolin/O. Pöggeler, Hamburg, 1959, \& 46, p. 70. 
justifica a concepção de dialética por ele elaborada. Aqui, ao contrário, estamos em plena dialética no sentido em que a tradição a concebeu desde Platão, ${ }^{64}$ isto é, no idealismo objetivo, que afirma que o conceito realmente existe, onde, portanto, a necessidade a priori se concilia com a contingência empirica a posteriori, portanto, onde se tematiza a unidade de forma e conteúdo. O importante em todo este procedimento argumentativo é mostrar que, no cerne da argumentação filosófica, no argumento de fundamentação última, há uma imbricação do argumento transcendental e do argumento dialético, o que significa dizer que a Filosofia é, em última análise, uma Ontologia transcendental-pragmaticamente mediada.

A Dialética é uma forma determinada de Ontologia, ou seja, é idealismo objetivo enquanto "conciliação da validade universalíssima de princípios do pensar e do ser com a contingência empirica da realidade de fato existente do mesmo pensar e ser" ${ }^{15}$ A Dialética trabalha com a unidade dos opostos: a necessidade não exclui, mas inclui, a contingência, o a priori e o a posteriori. Esta unidade de opostos é que merece o nome de Absoluto, que é tanto ser, como pensar, ou seja, unidade de ser e pensar, um Absoluto, portanto, que tem o relativo dentro de si. Neste sentido, pode-se dizer, como faz Hegel, que o Absoluto é, propriamente, o objeto da Filosofia: Filosofia é ciência do Absoluto.

O Absoluto, que é a totalidade enquanto sujeito lógico da predicação nas sentenças dialéticas, está, na realidade, sempre presente em cada passo do processo dialético: o todo está presente em cada uma de suas partes. Neste sentido, o que especifica a Filosofia é que ela é, sempre ciência da totalidade, cuja tarefa específi$\mathrm{ca}$, e isto a distingue das ciências, consiste em detectar a presença do todo nas partes. Aquela estrutura fundamental apriórica, que não podemos negar sem entrar em contradição performativa, está presente em tudo, está no âmago de cada ser, mas, ao mesmo tempo, os transcende a todos como o todo e por esta razão nunca pode, simplesmente, ser identificado com uma parte determinada.

Para Cirne Lima, como para Hegel, a Filosofia enquanto ciência do Absoluto se efetiva em dois momentos: em primeiro lugar, ela é logica, como tematização dos princípios fundamentais de todas as coisas, a partir de onde tudo pode ser penșado. Justamente aqui se põe a questão: como é possivel pensar tudo, ou seja, agora, toda e qualquer realidade na perspectiva do Absoluto? Como é possível construir sentenças dialéticas sobre as coisas contingentes que constituem o objeto de nossa experiência no mundo? Não é isto uma pretensão absurda, que a revolução reflexiva do pensamento moderno mostrou ilusória? O Absoluto é, também Natureza e História, ou seja, os diferentes campos da realidade empírica e histórica na qual estamos inseridos? Se não for, certamente retrocedemos a um pensamento formal que tem o conteúdo fora de si, o que contradiz a fundamentaçăo última. Se é, como se distingue deste primeiro momento de sua consideração enquanto lógi-

\footnotetext{
64 Enquanto ontólogo radical, na expressão de Hösle, que entende a filosofia como um sistema dinâmico, dialético, que supera as oposiçőes em si Cf. V. Hösle, Wahrheit und Geschichte. Studien zur Struktur der Philosophiegeschichte unter aradigmatischer Analyse der Entwicklung von Parmides bis Platon, Stuttgart/Bad-Cannstatt, 1984, p. 385-386.
} 
ca de tal modo que se justifique um segundo momento da Filosofia enquanto ciência do Absoluto?

Cirne Lima responde a estas questões apelando para o mecanismo da "reduplicaçãon ${ }^{n 6}$ que é um mecanismo lógico, já conhecido na Idade Média, para resolver as contradições, porque, através dele, é possível intercalar uma ou mais proposições entre o sujeito e o predicado, que tem o mesmo sujeito e que, acrescentando ao sujeito primeiro e principal novos aspectos, reduplica este sujeito. Ora, o que caracteriza a filosofia real é que, nela, o sujeito lógico é, sempre um sujeito reduplicado. O sujeito universal da predicação dialética é, como vimos, sempre o Absoluto. A questão agora é como trabalhar com o Absoluto de modo que seja possível captar toda a riqueza de nossa experiência. Ora, é possível, logicamente, enriquecer o sujeito lógico universalíssimo das proposições dialéticas, o Absoluto, através do mecanismo da ređuplicação.

Então, que é a filosofia real? Aquele momento do pensamento filosófico em que o Absoluto, continuando o sujeito principal de todas as sentenças, sem destruir e eliminar sua universalidade, se transforma num universal particularizado. 0 universal, pela reduplicação, se faz particular sem deixar de ser universal. Na reduplicação, o sujeito principal de uma proposição principal, através de duas proposições reduplicativas, torna-se um sujeito duplo sem perder sua unidade. É precisamente nisto que consiste a unidade dos opostos de que fala a tradição do pensamento dialético que, exatamente por esta razão, não precisa apelar para algo fora da reflexão filosófica, a práxis material dos sujeitos no mundo, para poder ter conteúdo. Este mecanismo torna possível uma consideração própria e estritamente filosófica dos objetos de nossa experiência, o que por sua vez não elimina a tarefa própria das ciências.

A tese lógica básica, que é condição de possibilidade da filosofia real, é: "o Absoluto pode, pois, tornar-se um sujeito que, sem deixar de ser o Absoluto uno e único que é, fica um sujeito duplo, ou seja, um Absoluto considerado, não enquanto é em si e de per si, mas enquanto é e determina algo outro em sua unidade originária". ${ }^{57} \mathrm{O}$ Absoluto continua, na filosofia real, como sujeito principal e originário da predicação, o que significa dizer que a filosofia real é filosofia mesmo e não uma pseudo-ciência particular, mas ele é determinado, ulteriormente, através da reduplicação. Neste caso, as proposições dialéticas da filosofia real têm como sujeito lógico o Absoluto enquanto se manifesta, se concretiza e se encarna numa determinada forma particular. Reaparece, aqui, neste segundo momento da reflexão filosófica, a mútua imbricação entre universal e particular, absoluto e relativo, necessário e contingente, ideal e real.

O Absoluto está, sempre, presente em suas partes, mas, em cada parte de maneira diversa. Assim, ele continua o sujeito lógico das proposições da filosofia real e, neste sentido, elas são idênticas às proposições da Lógica. É próprio da Lógica considerar todas as coisas em sua universalidade simplesmente. A especificidade das proposições da filosofia real é que, além deste sujeito que é comum ao da Ló-

66 Cf. C. R. V. Cime Lima, "A lógica do Absoluto", op. cit., p. 519 e ss.

67

Cf. C. R. V. Cirne Lima, "A lógica do Absoluto", op. cit., p. 523. 
gica, elas têm um outro sujeito, um sujeito secundário particular, originado pela mediação da reduplicação, o que as faz tematizar coisas no espaço e no tempo.

Ora, o que faz precisamente a filosofia real filosofia é que ela tematiza o particular em sua universalidade. Sem dúvida, ela tematiza os entes que estão em nossa experiência, no mundo da pluralidade, da contingência, da materialidade, da finitude. O propriamente filosófico nesta consideração específica do conteúdo do mundo consiste em procurar o universal ínsito no particular e que o constitui enquanto tal e a partir de onde se determina seu sentido. A ciência, nesta perspectiva, vê o particular, mas não enquanto particular, pois para isto é necessário captar o universal que, particularizando-se, constitui o particular enquanto particular. Assim, a diferença entre Filosofia e Ciência não se dá só em relação a dois tipos diferenciados de demonstração (dedução x reflexão) e à diferença entre saber formal e saber de conteúdos (tese básica da filosofia moderna, aceita pela pragmática transcendental), mas, antes, na maneira muito diferente de considerar o conteúdo do que encontramos em nossa experiência de mundo.

Como se articula, concretamente, o discurso dialético sobre algo contingente e histórico? Por tudo o que já foi exposto, a primeira coisa é a reduplicação do sujeito originário através da qual se obtém o novo sujeito. Como se obtém o predicado da proposição? Em princípio, se entendemos Filosofia como sistema abrangente, todos os predicados possíveis são candidatos a predicado destas proposições, todas as categorias da Lógica, como os predicados que ocorrem na filosofia real antes deste sujeito específico. Neste sentido, podemos dizer que, em cada figuração, ocorre uma recapitulação do sistema inteiro, recuperando-se, assim, os momentos precedentes, determinando-se mais tanto o sujeito lógico originário, quanto o sujeito reduplicado.

No entanto, todo este procedimento é marcado por uma inadequação básica: o sujeito reduplicado diz sempre mais (pragmaticamente) do que os predicados, semanticamente, conseguem exprimir. Nesse sentido é que se pode dizer, com Cirne Lima, que "todas essas proposições são, se tomadas ao pé da letra, falsas, porque põem como simplesmente idênticas coisas que são só parcialmente idênticas" ${ }^{68}$ No jogo de opostos, com que os dialéticos trabalham, a tese e antítese são duas proposições contrárias ambas falsas; as sínteses são verdadeiras, mas podem sempre, de novo, transformar-se em teses que são, também, falsas e assim, o processo até a síntese última do sistema, que recupera todos os momentos anteriores e onde se efetiva a adequação entre o pragmático e o semântico, porque, aqui, a expressão é completa e acabada. Assim se completa o trabalho da Dialética enquanto uma Ontologia com fundamentação última.

68 Cf. C. R. V. Cime Lima, "A lógica do Absoluto", op. cit., p. 527. 